\title{
Cyclohexenonic long-chain fatty alcohol has therapeutic effects on diabetes-induced angiopathy in the rat aorta
}

Chiko Shinbori, Motoaki Saito, Yukako Kinoshita, Itaru Satoh, Tomoharu Kono, Takuya Hanada, Eiji Nanba, Kaori Adachi, Hiroto Suzuki, Masashi Yamada and Keisuke Satoh

Department of Pathophysiological and Therapeutic Science, Division of Molecular Pharmacology, Tottori University Faculty of Medicine, Yonago, Japan (C.S., M.S., Y.K., I.S., T.K., T.H., K.S.), Division of Functional Genomics, Research Center for Bioscience and Technology, Tottori University, Yonago, Japan (E.N., K.A.), Meiji Dairies Corporation Pharmaceuticals Department, Tokyo, Japan (H.S., M.Y.)

\section{Correspondence:}

Motoaki Saito, MD, Ph.D

Department of Pathophysiological and Therapeutic Science, Division of Molecular Pharmacology, Tottori University Faculty of Medicine, 86 Nishimachi, Yonago, 683-8503, Japan

$$
\begin{aligned}
& \text { Telephone : } \quad+81-859-38-6163 \\
& \text { FAX : } \quad+81-859-38-6160 \\
& \text { e-mail address : saitomo@grape.med.tottori-u.ac.jp }
\end{aligned}
$$




\section{Abstract}

We studied the effects of cyclohexenonic long-chain fatty alcohol (N-hexacosanol) on

diabetes-induced angiopathy in the rat aorta. Male Sprague-Dawley rats were divided

into 4 groups, a control group and 3 other groups in which diabetes was induced by

streptozotocin (50 mg/kg i.p.). Four weeks after the induction of diabetes, the 3

groups received treatment with either vehicle or N-hexacosanol (2 or $8 \mathrm{mg} / \mathrm{kg}$, i.p. every

day) for another 4 weeks. To determine the mechanisms of diabetic vascular

dysfunction and the effects of N-hexacosanol, we conducted organ bath studies and

real-time polymerase chain reaction on muscarinic $\mathrm{M}_{3}$ receptor, and endothelial and

inducible nitric oxide synthase (eNOS and iNOS) mRNAs in the rat aorta. Treatment

with N-hexacosanol did not alter the diabetic status, but improved the diabetes-induced

hypercontraction produced by norepinephrine and the damaged endothelium-dependent

relaxation of the rat aorta induced by acetylcholine. Furthermore, in the diabetic rats,

both muscarinic $\mathrm{M}_{3}$ receptor and iNOS mRNAs were significantly increased, and

N-hexacosanol reversed these upregulations. However, the expression of eNOS

mRNA showed no change in all groups. These results indicate that N-hexacosanol has 
beneficial effects on functional dysfunction and reverses the upregulation of muscarinic $\mathrm{M}_{3}$ receptor and iNOS mRNAs in the diabetic rat aorta.

Key Words: N-hexacosanol, NOS, muscarinic $\mathrm{M}_{3}$ receptor, aorta, endothelium, diabetes 


\section{Introduction}

Cardiovascular disease is one of the leading causes of death in diabetes mellitus,

which alters vascular responsiveness to several vasoconstrictors and vasodilators and is a major factor underlying the development of this disease (Senses et al., 201). Most of the complications in diabetes are caused by increased serum glucose and the increased generation of oxygen-derived free radicals, which lead to endothelium dysfunction and neuropathy. Although strict glycemic control delays the onset and slows down the progression of diabetic vascular complications (The Diabetic Control and Complications Trial Research Group, 1993), this strategy is not successful in all patients. There have been many reports demonstrating functional changes in various smooth muscle cells from diabetic animals (Ozturk et al., 1996). It has been shown that vessels from diabetic animals exhibit abnormal endothelium-dependent vascular relaxation to acetylcholine (Oyama et al., 1986). These functional changes may be associated with endothelium dysfunction in diabetes. Impaired endothelium-dependent vasodilatation may arise from several mechanisms: decreased production of one of the endothelium-derived relaxing factors (EDRFs), including nitric 
oxide (NO ) and prostacyclin ( $\left.\mathrm{PGI}_{2}\right)$, enhanced inactivation of EDRF, impaired diffusion of EDRF to the underlying smooth muscle, and enhanced generation of endothelium-derived constricting factors (EDCF) (De Vriese et al., 2000). In particular, NO plays an important role in vasodilation. In 1980, Furchgott and Zawadzki described a mediator that is released by the vascular endothelium in response to acetylcholine and causes vascular smooth muscle relaxation (Furchgott and Zawadzki, 1980). NO is synthesized by three different NO-synthase (NOS) isoforms: inducible NOS (iNOS), brain-type (bNOS), and endothelial constitutive NOS (eNOS) (Forstmann et al., 1994). It is generally assumed that these three NOS enzyme isotypes play an important role in maintaining proper functions in homeostasis (Bode-Boger et al., 1996; Cooke and Tsao, 1997). However, under chronic proinflammatory conditions, such as those at work during arteriosclerosis, local expression of the iNOS isotype is seen in endothelia and other cell types (Wilcox et al., 1997). Furthermore, previous studies using pharmacological approaches with muscarinic receptor agonists and antagonists suggest that the muscarinic $\mathrm{M}_{3}$ receptor mainly mediates vasodilation via the actions of eNOS in the rat aorta (Boulanger et al., 1994; Khurana et al., 2004). It is well known 
that the muscarinic $\mathrm{M}_{3}$ receptor is mainly expressed in the endothelium in the aorta.

However, the extent of the contribution of the muscarinic $\mathrm{M}_{3}$ receptor to diabetic aortic dysfunction is not well known.

Cyclohexenonic long-chain fatty alcohol (N-hexacosanol) exhibits a wide variety of biological actions. A previous study showed that N-hexacosanol has neurotrophic activation on cultured neurons from the cerebral cortex (Borg et al., 1990). We have reported the ameliorative effects of $\mathrm{N}$-hexacosanol on diabetes-induced hyperreactivity of the bladder and trachea in the rat (Satoh et al., 2005; Suzuki et al., 2006; Saito et al., 2007). We have also reported that diabetes-induced hypercontraction of the aorta was ameliorated by treatment with N-hexacosanol (Kinoshita et al., 2006). However, the effect on hyporelaxation in the aorta is still unknown. From the above results, we hypothesized that $\mathrm{N}$-hexacosanol may have a beneficial effect on the muscarinic $\mathrm{M}_{3}$ receptor and on eNOS and iNOS in the diabetes-induced rat aorta.

In order to investigate the therapeutic effects of N-hexacosanol on diabetes-induced vascular dysfunction and reveal its molecular mechanisms, we conducted organ bath studies and quantification of the muscarinic $\mathrm{M}_{3}$ receptor and eNOS and iNOS mRNA in 
the rat aorta. 


\section{Materials and Methods}

\subsection{Animal model}

All animal experiments were performed in accordance with the guidelines established by the Tottori University Committee for Animal Experimentation. Diabetes was induced in 8-week-male Sprague-Dawley rats (SLC, Shizuoka, Japan) by administering an intraperitoneal injection of streptozotocin $(50 \mathrm{mg} / \mathrm{kg}$ ) dissolved in $0.1 \mathrm{M}$ citrate-phosphate buffer ( $\mathrm{pH} 4.2$ ), according to the method of our previous reports (Satoh et al., 2005; Suzuki et al., 2006; Kinoshita et al., 2006; Saito et al., 2007). The rats were divided randomly into 4 age-matched groups ( $\mathrm{n}=6-8)$. One group was the non-diabetic control (group A), and was administered the vehicle; diabetes was induced in the other three groups. Four weeks after the induction of diabetes, the three groups were treated for another 4 weeks with either vehicle (group B) or with N-hexacosanol at a daily dose of 2 or $8 \mathrm{mg} / \mathrm{kg}$ (groups $\mathrm{C}$ and $\mathrm{D}$, respectively). N-hexacosanol was dissolved in ethanol, then a mixture of physiological saline/ Tween 80 was added to obtain an ethanol: saline: Tween 80 ratio of 5: 92.15: 2.85 (total volume approximately $0.3 \mathrm{ml}$ ). The structure of the N-hexacosanol used in this study is shown in Fig. 1. 
Two days after the injection of streptozotocin or vehicle, the induction of diabetes was

confirmed by measuring urinary glucose with Pretest 3a II (Wako Pure Chemical, Osaka, Japan). Either Nhexacosanol (groups C and D) or vehicle (groups A and B) was injected i.p. every day beginning 4 weeks after the induction of diabetes, according to the method used in our previous reports (Satoh et al., 2005; Suzuki et al., 2006; Kinoshita et al., 2006; Saito et al., 2007). All groups were kept under identical conditions, with access to food and drinking water ad libitum. Eight weeks after the induction of diabetes, the rats were sacrificed with an overdose of pentobarbital (60 mg / animal, i.p.). Blood samples were collected from the vena cava, and the aorta was removed from each animal and placed in Krebs-Henseleit solution comprised of (mM): $\mathrm{NaCl}$ 118.0, $\mathrm{KCl}$ 4.7, $\mathrm{MgSO}_{4}$ 1.2, $\mathrm{CaCl}_{2}$ 2.5, $\mathrm{KH}_{2} \mathrm{PO}_{4}$ 1.2, $\mathrm{NaHCO}_{3}$ 24.9, glucose 5.6 and sodium pyruvate 2.0, for use in functional and biochemical studies.

\subsection{Serum glucose and insulin measurement}

Serum glucose concentrations in the experimental rats were measured by the hexokinase method (Glucose C II , Wako Pure Chemical, Osaka, Japan), which was carried out 
according to the kit manufacturer's instructions. Insulin concentrations were also

measured by ELISA according to the manufacturer's instructions (Rat Insulin ELISA, Mercodia AB, Uppsala, Sweden).

\subsection{In vitro organ bath experiments}

Functional studies were performed according to our previous report (Kinoshita et al.,

2006). The thoracic aortas were cut into approximately 3-mm-long ring segments.

Each ring was suspended on a wire hook in an organ bath (25 ml) containing

Krebs-Henseleit solution, and bubbled with $5 \% \mathrm{CO}_{2}$ and $95 \% \mathrm{O}_{2}\left(37^{\circ} \mathrm{C}\right)$. One hook was suspended from a transducer (type 45196A, San-ei Instruments, Tokyo, Japan), and the lower hook was fixed to a plastic support leg to a micrometer (Mitutoyo, Tokyo, Japan). Each ring was equilibrated unstretched for 30 minutes. A load of $0.5 \mathrm{~g}$ was applied to each ring by micrometer adjustment, and the load was readjusted to this level 30 minutes later. Changes in the tone were recorded by a force transducer on a personal computer (Macintosh G3, Apple Computer, Cupertino, CA) by use of Chart v 3.6.9 software and a PowerLab/16sp data acquisition system (AD Instruments, Castle 
Hill, Australia). Following a 30-minute period of equilibration, the rings were exposed to $100 \mathrm{mM} \mathrm{KCl}$. In the aorta rings, the contractile response to norepinephrine $(1 \mathrm{x}$ $10^{-9}-3 \times 10^{-6} \mathrm{M}$ ) was determined cumulatively. After a 30-minute washout period, propranolol $\left(1 \times 10^{-6} \mathrm{M}\right)$ was added to prevent the involvement of $\beta$-adrenoceptors. Endothelium-mediated relaxation was measured as a concentration-response curve to acetylcholine $\left(1 \times 10^{-8}-3 \times 10^{-5} \mathrm{M}\right)$ in rings precontracted with the submaximal dose of norepinephrine $\left(3 \times 10^{-7} \mathrm{M}\right)$. Endothelium-independent aortic relaxation in response to nitroglycerin $\left(1 \times 10^{-6} \mathrm{M}\right)$ was also measured in the rings.

\subsection{Real-time polymerase chain reaction (quantification of muscarinic $M_{3}$} receptor, eNOS and iNOS mRNAs)

Expressions of muscarinic $\mathrm{M}_{3}$ receptor, eNOS and iNOS mRNAs in the experimental aorta were measured by real-time polymerase chain reaction (PCR) methods. The mRNAs were purified by the RNeasy Mini Kit (Quiagen, Valencia, CA) according to the manufacturer's instructions. A reverse transcriptase mixture (28 $\mu \mathrm{l})$ containing 2 $\mu \mathrm{g}$ of total RNA was made and incubated at $37{ }^{\circ} \mathrm{C}$ for 60 minutes. Fifteen $\mu \mathrm{l}$ of the 
master mix was used for the real-time PCR, which was carried out using a LightCycler thermal cycler system with a LightCycler-FastStart Hybridization Probe kit according to the manufacturer's instructions (Roche Diagnostics, Tokyo, apan). The muscarinic $\mathrm{M}_{3}$ receptor (GeneBank Accession: NM_012527) primers and probe sequences were the following: primer forward (1227-1245: 5’GGACTGTGGATGTGGAGAG-3’), primer reverse (1358-1375: 5’-CGAGGAGTTGGTGTCAGA-3’) and probe forward (1267-1284: 5’-CCA GAAGAGCATGGGTGATGGTGACAACT-3’), probe reverse (1286-1325: 5'-XGTCAGAAGGATTTCACCAAGC-TTCCCATCCT-3’). The pimer and probe of the $\beta$-actin (GeneBank Accession: NM_031144) and eNOS (GeneBank Accession: AJ011116) and iNOS (GeneBank Accession: D44591) used were from the LightCycler-Primer/Probe Set (rat) (Roche Diagnostics, Tokyo, Japan). A total of $5 \mu \mathrm{l}$ of template was used for the sample. The specificity of the reaction was confirmed by $2 \%$ agarose gel electrophoresis. The primers for the $\beta$-actin gene were used as the internal standard and gene levels were analyzed by real-time PCR using the same reverse transcriptase mixture. 


\subsection{Data analysis}

The data for the contractions induced by norepinephrine were normalized by the contractions induced by $100 \mathrm{mM} \mathrm{KCl}$. The relaxation responses with submaximal contraction caused by $3 \times 10^{-7} \mathrm{M}$ norepinephrine were expressed as percentages of nitroglycelin. The $\mathrm{ED}_{50}$ and $\mathrm{E}_{\max }$ values were obtained using a Macintosh computer (G3) loaded with Chart v3.6.9 software and a PowerLab/16sp data acquisition system. The $\mathrm{ED}_{50}$ values were calculated as geometric means, whereas the $\mathrm{E}_{\max }$ values were calculated as arithmetic means. The expressions of muscarinic $\mathrm{M}_{3}$ receptor, eNOS and iNOS mRNAs were quantified according to the expression of $\beta$-actin mRNA in the experimental rat aorta. A statistical comparison of differences between groups was performed using analysis of variance and Fisher's multiple comparison tests. $\quad \mathrm{P}<0.05$ was regarded as the level of significance.

\subsection{Drugs and chemicals}

3-(15 Hydroxypentadecyl)-2,4,4-trimethyl-2-cyclohexen 1-one (N-hexacosanol) was

obtained from Meiji Milk Products Co., Ltd., Tokyo, Japan. Propranolol and 
norepinephrine were purchased from Sigma (St. Louis, MO), and nitroglycerin

(millisrol $^{\circledR}$ ) was purchased from Nihonkayaku Co., Ltd. (Tokyo, Japan).

Streptozotocin was purchased from Wako Pure Chemical Co. (Osaka, Japan). All

other chemicals were available commercially and of reagent grade. 


\section{Results}

\subsection{General features of the experimental animals}

The data obtained for the general features and serum concentrations of insulin and glucose in the experimental animals are shown in Table 1. The diabetic rats that were not treated with N-hexacosanol showed no weight gain during the experimental period. The diabetic rats displayed significantly higher serum glucose and lower serum insulin levels than the control rats. Treatment with N-hexacosanol (at either 2 or $8 \mathrm{mg} / \mathrm{kg}$ ) neither increased body weight and insulin levels nor reduced serum glucose in the diabetic animals.

\subsection{Measurement of contraction (A) and relaxation (B)}

A: In the diabetic rat aortic rings, the contraction produced by norepinephrine was augmented (Fig. 2A). With treatment of $\mathrm{N}$-hexacosanol (8 $\mathrm{mg} / \mathrm{kg})$, the maximum contraction was significantly attenuated toward that obtained using control rat aortic rings (Fig. 2A). The maximum contraction $\left(\mathrm{E}_{\max }\right)$ and $\mathrm{EC}_{50}$ values are shown in Table 2. 
B: The maximum relaxation $\left(\mathrm{E}_{\max }\right)$ and $\mathrm{EC}_{50}$ values are shown in Table $2 . \quad$ In the aortic rings precontracted by norepinephrine with intact endothelium obtained from all groups, the relaxation was produced in a dose-dependent manner (Fig. B). The relaxation was markedly reduced in the diabetic aorta (Fig. 2B). With treatment of $\mathrm{N}$-hexacosanol, the attenuated relaxation was recovered; data are shown in Fig. 2B. Induction of diabetes significantly increased $\mathrm{EC}_{50}$ values for acetylcholine-induced relaxation. Treatment with either dose of N-hexacosanol, however, did not ameliorate these increased $\mathrm{EC}_{50}$ values. The ntroglycerin-induced relaxation was not changed in any groups (Table 2).

\subsection{Measurement of muscarinic $M_{3}$ receptor, eNOS and iNOS mRNAs in}

\section{the aorta}

Fig. 3 shows the expression of muscarinic $\mathrm{M}_{3}$ receptor, eNOS and iNOS mRNAs in the aorta. No significant difference in the eNOS mRNA levels was found between any groups while the $\mathrm{M}_{3}$ receptor and iNOS mRNA levels were significantly higher in the diabetes than in the control group. In addition, N-hexacosanol reversed these increases 
in a dose-dependent manner (Fig. 3). 


\section{Discussion}

In the diabetic state, the rat aorta exhibited enhanced vascular reactivity to norepinephrine and impairment of endothelium-dependent-relaxation by acetylcholine. While the eNOS mRNA level was not changed, the muscarinic $\mathrm{M}_{3}$ receptor and iNOS mRNA levels were significantly increased in the diabetic aorta. Although N-hexacosanol did not improve the general features or levels of serum glucose and insulin in the diabetic rats, it significantly improved the enhanced contraction produced by the $\alpha_{1}$-agonist norepinephrine and the impairment of endothelium-dependent relaxation induced by acetylcholine in a dose-dependent manner.

Previous reports demonstrated that aortic rings prepared from rats with streptozotocin-induced diabetes showed increased contraction in response to vasoconstrictor agents and reduced relaxation in response to endothelium-dependent relaxant agents, but not to endothelium-independent relaxant agents (Oyama et al., 1986; Pieper et al., 1998; Kinoshita et al., 2006). Previously, we demonstrated that maximum relaxation in response to nitroglycerin was only around $50 \%$ in Kinoshita's report, while maximum relaxation in response to nitroglycerin exceeded $90 \%$ in this 
study (Kinoshita et al., 2006). In Kinoshita’s reports, submaximal contraction was induced by the thromboxane $\mathrm{A}_{2}$ analogue $\mathrm{U} 46619$ at a molar dose of $3 \times 10^{-8}$, while in this experiment, we chose the physiological agonist norepinephrine. Submaximal contraction was induced by norepinephrine at a molar dose of $3 \times 10^{-7}$. The extents of contraction produced with agonists were distinct. The contraction produced by U46619 was stronger than that by norepinephrine. The extent of relaxation by nitroglycerin might be smaller than that by norepinephrine (Satoh et al., 1993). In this study, we carefully observed the contractile responses induced by norepinephrine, and decided that submaximal contraction was induced by norepinephrine at a molar dose of $3 \times 10^{-7}$. This may be the reason we obtained maximum relaxation in response to nitroglycerin exceeding $90 \%$ in this study. In this study, although the degree of relaxation induced by acetylcholine was significantly improved by the high dose of N-hexacosanol, the $\mathrm{EC}_{50}$ values for acetylcholine were not reversed by this dose. These data suggest that the affinity of the endothelium for acetylcholine was not reversed by treatment with $\mathrm{N}$-hexacosanol.

Diabetes mellitus has been reported to induce hyperglycemia and injured vascular 
endothelial cells and peripheral nerve cells (Oyama et al., 1986; Ozturk et al., 1996;

Shinozaki et al., 2003). Previous studies have shown that N-hexacosanol treatment has no effect on serum glucose and insulin levels of diabetic rats (Satoh et al., 2005; Suzuki et al., 2006; Kinoshita et al., 2006; saito et al., 2007). Therefore, the finding that this drug does not influence the serum glucose levels indicates that the mechanisms of its reversible effect on the diabetic rat aorta do not occur by reducing serum glucose.

To clarify the mechanism of the ameliorative effect of N-hexacosanol, we performed quantification of muscarinic $\mathrm{M}_{3}$ receptor, eNOS and iNOS mRNAs by real-time PCR. In the PCR studies, while the eNOS mRNA level was not changed, the muscarinic $\mathrm{M}_{3}$ receptor and iNOS mRNA levels exhibited significant increases in the induced diabetic aorta. Previous studies suggested that arterial endothelium cells released acetylcholine (Kawashima et al., 1990; Ikeda et al., 1994), and the endothelium dysfunction-induced diabetic states might bring about a reduction in acetylcholine release. Therefore, muscarinic $\mathrm{M}_{3}$ receptor mRNA might be upregulated in diabetes. And, because eNOS is expressed in endothelial cells, endothelium dysfunctions reduce the eNOS expression. In fact, it has been reported that hyperglycemia and glucose-modified proteins reduce 
constitutive NOS expression (Chakravarthy et al., 1998). Bojunga et al reported that eNOS mRNA levels were decreased in the diabetic rat aorta (Bojunga et al., 2004). As competitive reverse-transcriptase PCR is more sensitive than real-time PCR, the reasons for these different results may be due to the small differences detected by real-time PCR. The diabetic status of the animals in other experiments was different from that in ours. Furthermore, the muscarinic $\mathrm{M}_{3}$ receptor activation on endothelial cells produces NO via eNOS and $\mathrm{PGI}_{2}$ via phospholipase A2 and arachidonic acid (Jaiswal et al., 1991; Kan et al., 1995; Maguire and Davenport, 2005; Triggle et al., 2003). The PG I pathway may be related to this event. The result obtained for the iNOS mRNA was in agreement with that of a previous study (Bojunga et al., 2004). The results of the present study demonstrate that eNOS and iNOS are regulated differentially in experimental diabetes mellitus. Hyperglycemia and glucose-modified proteins may act to reduce eNOS activity and at the same time increase iNOS gene expression with enhanced NO release. It is also suggested that hyperglycemia markedly activates the $\beta \mathrm{II}$ isoform of protein kinase $\mathrm{C}(\mathrm{PKC})$ in endothelial cells by promoting de novo synthesis of diacylglycerol (DAG) and increasing mitochondrial superoxide production. 
Activated PKC can indeed negatively influence transcription of eNOS while acting positively on the iNOS gene (Bojunga et al., 2004). It is known that iNOS is induced by inflammation, and that iNOS-derived NO exhibits a powerful protective activity towards cellular stress conditions (Buttery et al., 1996). Moreover, other studies have shown that iNOS-derived NO serves to modulate the expression of many different genes that also affect protective responses during stress conditions (Ehrt et al., 2001; Hemmrich et al., 2003). It is possible that iNOS does not contribute directly to the induction of relaxation, but has other responses protecting the vascular endothelium. Previous experimental evidence has suggested that tetrahydrobiopterin $\left(\mathrm{BH}_{4}\right)$, the natural and essential cofactor of NOS, plays a crucial role not only in increasing the rate of NO generation by NOS, but also in controlling the formation of superoxide anions $\left(\mathrm{O}_{2}{ }^{-}\right)$in endothelial cells (Baek et al., 1993). In fact, oral supplementation with $\mathrm{BH}_{4}$ restored endothelial function and relieved oxidative tissue damage through the activation of eNOS in the aortas of insulin-resistant rats (Pieper et al., 1997; Shinozaki et al., 2003). It is possible that the influence of eNOS-derived NO production on hyporelaxation is mediated via other factors or stages. 
Jover et al. reported that N-hexacosanol may act directly upon nerve terminals

inducing $\mathrm{Ca}^{2+}$ entry and hence promote neurohormone release (Jover et al., 2005). As

muscarinic $\mathrm{M}_{3}$ receptor subtypes, eNOS and iNOS are expressed in the aortic smooth

muscle (Ehlert, 2003). In order to reveal more details and the precise mechanisms of

this effect, further studies are needed. Taken together, our data demonstrate that

N-hexacosanol normalized the dysfunction of relaxation, and reversed diabetes-induced

upregulation of muscarinic $\mathrm{M}_{3}$ receptor and iNOS mRNAs.

\section{Acknowledgments}

This study was supported by a grant from the Ministry of Education, Science, and

Culture of Japan (\#14704041) and by a research grant from the President of Tottori

University (2005). 


\section{Reference}

Baek, K.J., Thiel, B.A., Lucas, S., Stuehr, D.J., 1993. Macrophage nitric oxide synthase subunit: purification, characterization, and role of prosthetic groups and substrate in regulating their association into a dimeric enzyme. J. Biol. Chem. 268, 21120-21129.

Bode-Boger, S.M., Boger, R.H., Kienke, S., Junker, W., Frolich, J.C., 1996. Elevated L-arginine/dimethylarginine ratio contributes to enhanced systemic NO production by dietary L-arginine in hyperholesterolemic rabbits. Biochem. Biophys. Res. Commun. 219, 598-603.

Brog. J., Kesslak, P.J., Cotman, C.W., 1990. Peripheral administration of a long-chain fatty alcohol promotes septal cholinergic neurons survival after fimbria-fornix transection. Brain Res. 518, 295-298.

Bojunga, J., Dresar-Mayert, B., Usadel, K., Kusterer, K., Zeuzem, S., 2004.

Antioxidative treatment reverses imbalances of nitric oxide synthase isoform expression 
and attenuates tissue-cGMP activation in diabetic rats. Biochem. Biophys. Res.

Commun. 316, 771-780.

Boulanger, C.M., Morrison, K.J., Vanhoutte, P.M., 1994. Mediation by M3-muscarinic receptors of both endothelium-dependent contraction and relaxation to acetylcholine in the rat aorta $\mathrm{f}$ the spontaneously hypertensive rat. Br. J. Pharmacol. 112, 519-524.

Buttery, L.D., Springall, D.R., Chester, A.H., Evans, T.J., Standfield, E.N., Parums, D.V., Yacoub, M.H., Polak, J.M., 1996. Inducible nitric oxide synthase is present within human atherosclerotic lesions and promotes the formation and activity of peroxynitrite.

Lab. Invest. 75, 77-85.

Chakravarthy, U., Hayes, R.G., Stitt, A.W., McAuley, E., Archer, D.B., 1998.

Constitutive nitric oxide synthase expression in retinal vascular endothelial cells is suppressed by high glucose and advanced glycation end products. Diabetes 47, 945-952. 
Cooke, J.P., Tsao, P.S., 1997. Arginine: a new therapy for atherosclerosis? Circulation 95, 311-312.

De Vriese, A., Verbeuren, T.J., Van de Voorde, J., Lameire, N.H., Vanhoutte, P.M., 2000.

Endothelial dysfunction in diabetes. Br. J. Pharmacol. 130, 963-974.

The Diabetic Control and Complications Trial Research Group, 1993. The effect of intensive treatment of diabetes on the development and progression of long-term complications in insulin-dependent diabetes mellitus. N. Eng. J. Med.329, 977-986.

Ehlert, F.J., 2003. Pharmacological analysis of contractile role of M2 and M3 muscarinic receptors in smooth muscle. Receptors Channels 9, 261-277.

Ehrt, S., Schnappinger, D., Bekiranov, S., Drenkow, J., Shi, S., Gingeras, T.R., Gaasterland, T., Schoolnik, G., Nathan, C., 2001. Reprogramming of the macrophage transcriptome in response to interferon-gamma and and Mycobacterium tuberculosis: 
signaling roles of nitric oxide synthase-2 and phagocyte oxidase. J. Exp. Med. 194, 1123-1140.

Forstemann, U., Closs, E.I., Pollock, J.S., Nakane, M., Schwarz, P., Gath, I., Kleinert, H., 1994. Nitric oxide synthase isozymes. Characterization, purification, molecular cloning, and functions. Hypertension 23, 1121-1131.

Furchgott, R.F., Zawadzki, J.V., 1980. The obligatory role of endothelial cells in the Relaxation of arterial smooth muscle by acetylcholine. Nature 288, 373-376.

Hemmrich, K., Suschek, C.V., Lerzynski, G., Kolb-Bachofen, V., 2003. iNOS activity essential for endothelial stress gene expression protecting against oxidative damage. J. Appl. Physiol. 95, 1937-1946.

Ikeda, C., Morita, I., Mori, A., Fujimoto, K., Suzuki, T., Kawashima, K., Murota, S., 1994. Phorbol ester stimulates acetylcholine synthesis in cultured endothelial cells 
isolated from porcine cerebral microvessels. Brain Res. 655, 147-152.

Jaiswal, N., Jaiswal, R.K., Malik, K.U., 1991. Muscarinic receptor-mediated prostacyclin and cGMP synthesis in cultured vascular cells. Mol. Pharmacol. 40, 101-106.

Jover, E., Gonzalez de Aguilar, J.L., Luu, B., Lutz-Bucher, B., 2005. Effect of a cyclohexenonic long-chain fatty alcohol on calcium mobilization. Eur. J. Pharmacol. 516, 197-203.

Kan, H., Ruan, Y., Malk, K.U., 1995. localization and characterization of subtype(s) of muscarinic receptor involved in prostacyclin synthesis in rabbit heart. J. Pharmacol. Exp. Ther. 276, 934-941.

Kawashima, K., Watanabe, N., Oohata, H., Fujimoto, K., Suzuki, T., Ishizaki, Y., Morita, I., Murota, S., 1990. Synthesis and release of acetylcholine by cultured bovine arterial 
endothelial cells. Neurosci. Lett. 119, 156-158.

Khurana, S., Chacon, I., Xie, G., Yamada, M., Wess, J., Raufman, J.P., Kennedy, R.H., 2004. Vasodilatory effects of cholinergic agonists are greatly diminished in aorta from M3R $^{-/-}$mice. Eur. J. Pharmacol. 493, 127-132.

Kinoshita, Y., Saito, M., Satoh, I., Shomori, K., Suzuki, H., Yamada, M., Kono, T., Satoh, K., 2006. General administration of cyclohexenonic long-chain fatty alcohol ameliorates hyperreactivity of STZ-induced diabetic rat aorta. Life Sci. 78, 1508-1514. Maguire, J.J., Davenport, A.P., 2005. Regulation of vascular reactivity by established and emerging GPCRs. Trends in Pharmacol. Sci. 26, 448-454.

Ozturk, Y., Altan, V.M., Yildizoglu-Ari, N., 1996. Effects of experimental diabetes and insulin on smooth muscle functions. Pharmacological Reviews 48, 69-112. 
Oyama, Y., Kawasaki, H., Hattori, Y., Kanno, M., 1986. Attenuation of

endothelium-dependent relaxation in aorta from diabetic rats. Eur. J. Pharmacol. 131, 75-78.

Pieper, G.M., Gross, G.J., 1988. Oxygen free radicals abolish endothelium-dependent relaxation in diabetic rat aorta. Am. J. Physiol. 255, H825-H833.

Pieper, G.M., Langenstroer, P., Siebeneich, W., 1997. Diabetic-induced endothelial dysfunction in rat aorta: role of hydroxyl radicals. Cardiovasc. Res. 34, 145-156.

Saito, M., Kinoshita, Y., Satoh, I., Shinbori, C., Suzuki, H., Yamada, M., Watanabe, T., Satoh, K., 2007. Ability of cyclohexenonic long-chain fatty alcohol to reverse diabetes-induced cystopathy in the rat. Eur. Urol. 51, 479-488.

Satoh. I., Saito. M., Kinoshita, Y., Shomori, K., Suzuki, H., Yamada, M., Kono, T., Satoh, K., 2005. Effects of cyclohexenonic long-chain fatty alcohol on diabetic rat 
trachea. Life Sci.77, 2030-2039.

Satoh, K., Mori, T., Yamada, H., Taira, N., 1993. Nicorandil as a nitrate, and cromakalim as a potassium channel opener, dilate isolated porcine large coronary arteries in an agonist-nonselective manner. Cardiovasc. Drugs Ther. 7, 691-699.

Senses, V., Ozyazgan, S., Ince, E., Tuncdemir, M., Kaya, F., Ozturk, M., Sultuybek, G. Akkan, A.G., 2001. Effect of 5-aminoimidazole-4-carbox-amide riboside (AICA-r) on isolated thoracic aorta responses in streptozotocin-diabetic rats. J. Basic. Clin. Physiol. Pharmacol. 12, 227-248.

Shinozaki, K., Kashiwagi, A., Masada, M., Okamura, T., 2003. Stress and Vascular Responses: Oxidative stress and endothelial dtsfunction in the insulin-resistant state. J. Pharmacol, Sci, 91, 187-191.

Suzuki, H., Saito, M., Kinoshita, Y., Satoh, I., Kono, T., Shinbori, C., Anastasios, S., 
Yamada, M., Satoh, K., 2006. Preventive effects of cyclohexenonic long-chain fatty alcohol on diabetic cystopathy in the rat. Can. J. Physiol. Pharmacol. 84, 195-201. Triggle, C.R., Hollenberg, M., Anderson, T.J., Ding, H., Jiang, Y.-F., Ceroni, L., Wiehler, W.B., Ng, E.S.M., Ellis, A., Andrews, K., McGuire, J.J., Pannirselvam, M., 2003. The endothelium in health and disease- A target for therapeutic intervention. J. Smooth Muscle Res. 39, 249-267.

Wilcox, J.N., Subramanian, R.R., Sundell, C.L., Preiser, J.C., 1997. Effects of multiple isoforms of nitric oxide synthase in normal and atherosclerotic vessels. Arterioscler Thromb. Vasc. Biol, 17, 2479-2488. 


\section{Figure legends}

Fig. 1. The chemical structure of N-hexacosanol used in this study.

Fig. 2. a) Contractile response of rat aortic rings to norepinephrine. The data of

contraction induced norepinephrine were normalized by the $\mathrm{KCl}(100 \mathrm{mM})$. NE:

norepinephrine. b) Endothelium-dependent relaxation of rat aortic rings to

acetylcholine. The data of relaxation were normalized by the nitroglycerine. Ach:

acetylcholine. A: control rats, B: diabetic rats, C: diabetic rats treated with

N-hexacosanol (2 mg/kg), and D: diabetic rats treated with N-hexacosanol (8 mg/kg).

Data are shown as mean \pm S.E.M. of six to eight separated determinations in each group.

*) significantly different from the other groups. **) Significantly different from B

group. $* * *)$ Significantly different from B and C groups. $(\mathrm{p}<0.05)$

Fig. 3. a) Muscarinic $M_{3}$ receptor mRNA normalized by $\beta$-actin. b) eNOS mRNA

normalized by $\beta$-actin. c) iNOS mRNA normalized by $\beta$-actin. A: control rats, B:

diabetic rats, C: diabetic rats treated with $\mathrm{N}$-hexacosanol (2 mg/kg), and D: diabetic rats

treated with N-hexacosanol (8 mg/kg). Data are shown as mean \pm S.E.M. of six to

eight separated determinations in each group. *) Significantly different from A group. 
Table 1. General features of the experimental rats

\begin{tabular}{|c|c|c|c|c|c|}
\hline & 8 weeks old & 12 weeks old & 16 weeks old & Serum glucose (mg/dl) & Serum insulin $(\mu \mathrm{g} / \mathrm{l})$ \\
\hline A & $242.9 \pm 3.0$ & $423.6 \pm 5.9$ & $498.8 \pm 10.1$ & $172.8 \pm 13.9$ & $2.39 \pm 0.660$ \\
\hline C & $250.4 \pm 4.7$ & $251.0 \pm 17.0^{\mathrm{a}}$ & $229.0 \pm 25.4^{\mathrm{a}}$ & $314.4 \pm 46.9^{a}$ & $0.17 \pm 0.010^{\mathrm{a}}$ \\
\hline $\mathrm{D}$ & $253.3 \pm 5.1$ & $257.0 \pm 16.1^{\mathrm{a}}$ & $237.0 \pm 17.1^{\mathrm{a}}$ & $364.8 \pm 34.3^{\mathrm{a}}$ & $0.16 \pm 0.004^{\mathrm{a}}$ \\
\hline
\end{tabular}

A: control rats, B: diabetic rats treated with sham, C: diabetic rats treated with N-hexacosanol (2 mg/kg), and D: diabetic rats treated with $\mathrm{N}$-hexacosanol $(8 \mathrm{mg} / \mathrm{kg})$. Data are shown as mean \pm S.E.M. of six to eight separated determinations in each group. ${ }^{\mathrm{a}}$ ) Significantly different from the A group. 
Table 2. Data of functional studies in the rat aorta

\begin{tabular}{|c|c|c|c|c|c|c|}
\hline & \multicolumn{2}{|c|}{ Contraction } & \multicolumn{4}{|c|}{ Relaxation } \\
\hline & \multicolumn{2}{|c|}{ Noeepinephrine } & \multicolumn{2}{|l|}{ Acetylcholine } & \multicolumn{2}{|c|}{ Nitroglycerin } \\
\hline & $\operatorname{Emax} / \mathrm{KCl}(100 \mathrm{mM})$ & $\mathrm{EC}_{50}(\mathrm{e}-8 \mathrm{M})$ & Maximum relaxation ( \% ) & $\mathrm{EC}_{50}(\mathrm{e}-7 \mathrm{M})$ & $\operatorname{Max}$ & $\mathrm{n}$ relaxation $(\%)$ \\
\hline A & $1.67 \pm 0.03$ & $3.58 \pm 0.70$ & $68.26 \pm 3.14$ & $0.54 \pm 0.07$ & & $91.76 \pm 2.54$ \\
\hline B & $2.15 \pm 0.08^{\mathrm{a}}$ & $2.74 \pm 0.81$ & $29.81 \pm 6.15^{\mathrm{a}}$ & $2.28 \pm 0.67^{\mathrm{a}}$ & & $96.46 \pm 2.03$ \\
\hline $\mathrm{C}$ & $2.04 \pm 0.13^{\mathrm{a}}$ & $3.09 \pm 0.77$ & $27.36 \pm 4.89^{\mathrm{a}}$ & & $.44^{a}$ & $95.92 \pm 2.42$ \\
\hline $\mathrm{D}$ & $1.86 \pm 0.10^{\mathrm{a}, \mathrm{b}}$ & $3.64 \pm 1.22$ & $53.52 \pm 4.84^{\mathrm{a}, \mathrm{c}}$ & $2.68 \pm 0.49^{\mathrm{a}}$ & & $97.17 \pm 1.18$ \\
\hline
\end{tabular}

A: control rat, B:diabetic rat, C: diabetic rat with treatment with $\mathrm{N}$-hexacasanol $(2 \mathrm{mg} / \mathrm{kg})$, and D: diabetic rat with treatment with $\mathrm{N}$-hexacosanol (8mg/kg). The relaxation responses with submaximal contraction caused by $3 \times 10^{-7} \mathrm{M}$ norepinephrine were expressed as percentages of nitroglycelin. Emax and $\mathrm{EC}_{50}$ values under contraction are for norepinephrine. Maximum relaxation and $\mathrm{EC}_{50}$ values are for acetylcholine in aorta precontracted with norepinephrine. The relaxation responses to nitroglycerine as the percentage of the submaximum contraction obtained with norepinephrine. Data are shown as mean \pm S.E.M. of six to eight separated determinations in each group. $\quad{ }^{a}$ )Significantly different from A group. $\left.\quad{ }^{b}\right)$ Significantly different from B group. ${ }^{\mathrm{c}}$ )Significantly different from B and C groups. $(\mathrm{p}<0.05)$ 


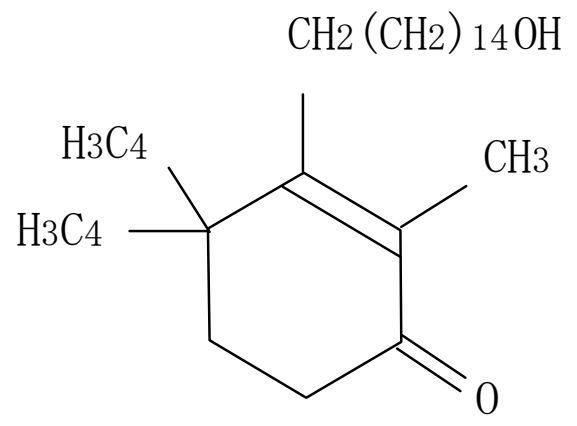


Figure 2. Measurement of contraction and relaxation
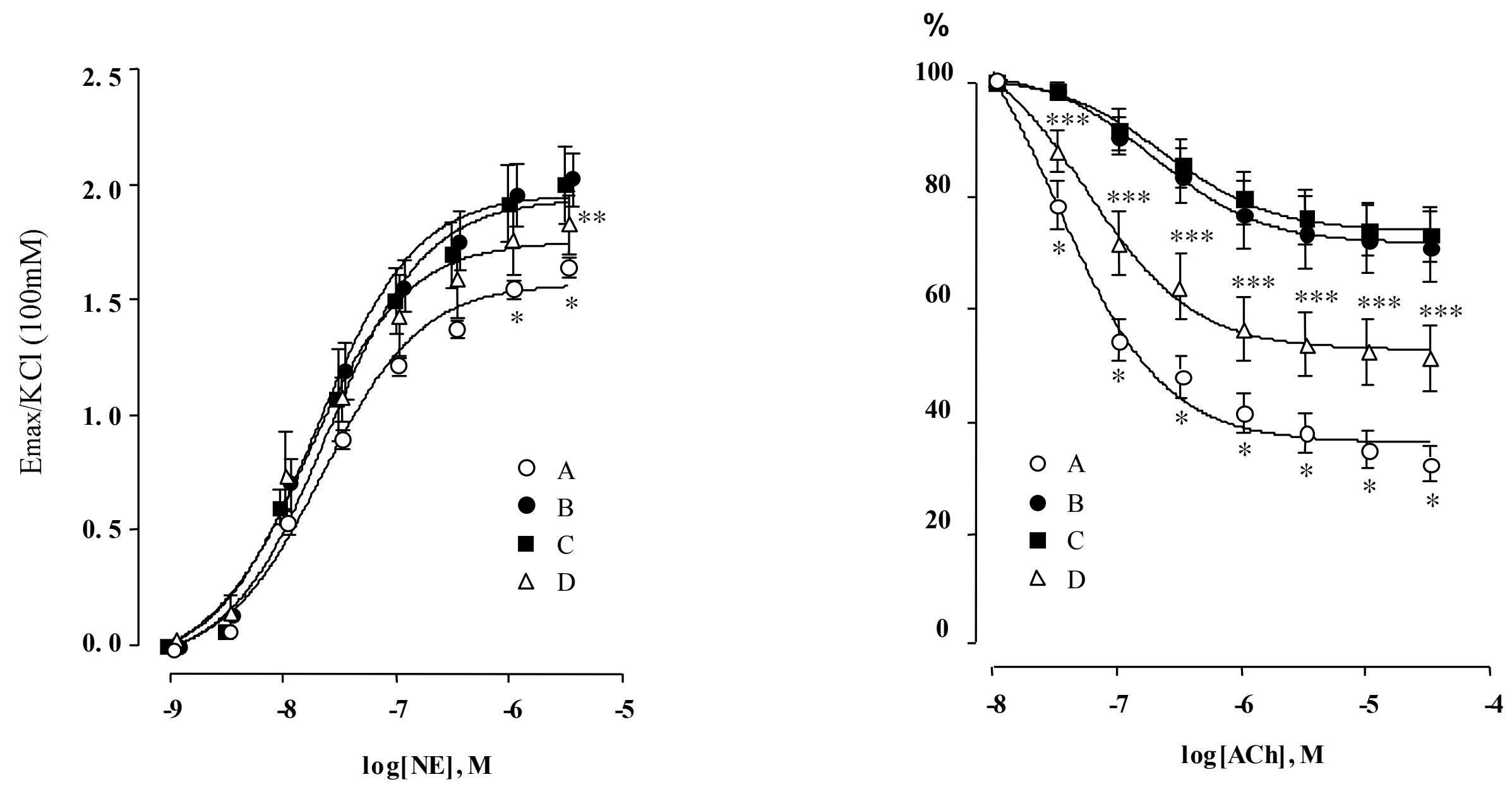
Figure 3. Expression of mRNAs in the rat
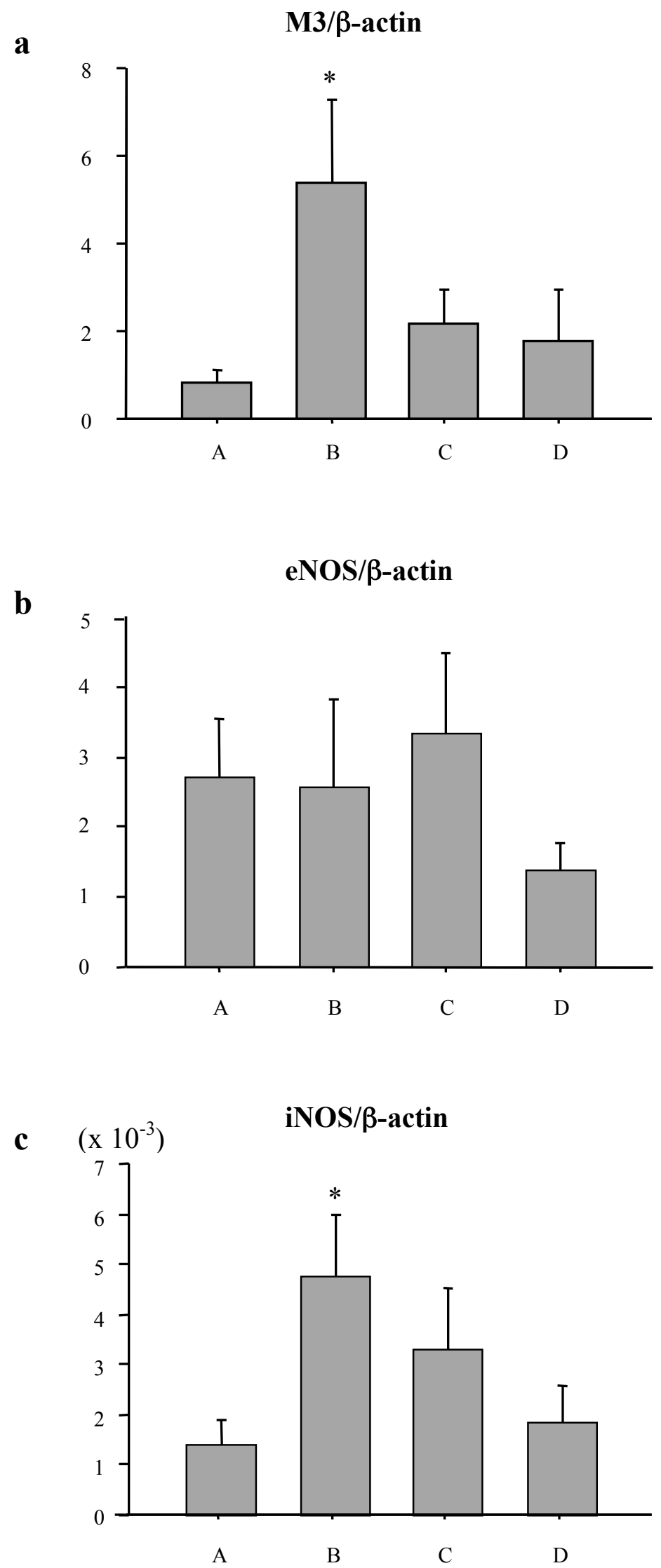